\title{
Sea versus PC
}

William H. Press

A View of the Sea: A Discussion Between a Chief Engineer and an Oceanographer about the Machinery of the Ocean Circulation. By Henry Stommel. Princeton University Press: 1987. Pp. 165. \$19.95, $£ 12.60$.

Henry Stommel, who is now approaching the age of retirement, is an extraordinary figure in post-war physical oceanography. He was responsible for the foundations of our modern understanding of oceanic circulation, and is famous as a raconteur, tinkerer, amateur explosives maker, backyard railroader. More importantly, he is celebrated for an uncanny physical intuition about how the ocean works.

A few years ago, Stommel began to write fascinating, off-beat, popular books: one, Volcano Weather on the so-called Year Without A Summer (1816), another on islands which appear on historical nautical charts, but subsequently vanish. No surprise, then, that the Sloan Foundation should ask him to contribute a personal autobiography to their distinguished series. In these times, scientists no less than starlets are encouraged to bare all.

Stommel did decide to write a personal book, but not under the Sloan Foundation's auspices. A View of the Sea is personal, after a fashion: cranky, idiosyncratic, uncompromising. There is little more than an occasional paragraph or two of autobiography in this book, and only a tease of shipboard anecdote. Stommel's idea of a personal book is not to take us into his life, but rather to try to take us into his mental spaces, to show us exactly how he thinks about ocean circulation. The result is fascinating, even when it can hardly be termed accessible.

Stommel thinks not in equations (certainly not in partial differential equations), but rather in pictures and force diagrams. Slabs of ocean water overlay other slabs. They tilt, slide on each other, thicken, thin, react to the strong constraints of the Coriolis force and the geometry of the two-sphere. "Then, by Rule 2, I found the $\mathrm{GV}$ [geostrophic velocity] in $a$ relative to $b$. Now, Rule 3 demands that the actual $\mathrm{GV}$ in layer $a$ (let's call it $\mathrm{GVa}$ ) must be parallel to the PT [potential thickness: thickness divided by sine of latitude] lines in $a$, and that GVb must lie parallel to the PT lines in $b$." There are pages and pages of this kind of thing.

What does one learn by working (I do mean working) it through? Quite a lot, if, like me, you are not an oceanographer. Because of the Coriolis force, ocean water does not flow in the direction that the wind pushes it, but at right angles to that direction. Westerlies in the North Atlantic (which blow to the east) thus drive water south; but trade winds to the south blow to the west and drive water north. The water has nowhere to go but down (this is Ekman pumping). Then where does it go? To accept the further fluid pumped down on top of it, and to be geostrophic, it has to move to a region where the Coriolis force is weaker, that is, south.

This cold, broad layer of North Atlantic water continues to be driven south. It goes deeper, and spreads laterally, as successively warmer layers are laid down on top of it. Conservation of mass must require a reverse, northwards, flow somewhere. However, geostrophic flow and conservation of potential vorticity (Stommel has his own odd way of explaining this) explicitly forbid such a return. Something has to give, and it does. At the western edge of the basin there can be a dissipative boundary layer which breaks some conservation laws. The result is the Gulf Stream (in the Pacific, the Kuroshio), with a fast core jet that is able to cross isobars (violate geostrophy), and transport vorticity internally. It all fits together. Stommel calls it a Chinese puzzle.

In Chapter 11, the narrative takes a

\section{The ice man}

\section{Derek Fordham}

The Ice: A Journey to Antarctica. By Stephen J. Pyne. University of Iowa Press/ Arlington Books, 15-17 King Street, St James's, London SW1: 1986-1987. Pp.428. \$37.50, £12.95.

A NACREOUS mass spins in the gyre of the Antarctic Ocean; almost imperceptibly it hesitates and disappears in a veil of fog and pack ice. This is ice, the ice of the title and The Ice (always in capitals) which is the book's leitmotiv. All its forms, from frazil to vuggy, are encountered and meticulously described as succeeding pages follow the gyrating iceberg from diamond dust to disintegration.

At first, mankind has little place in Stephen Pyne's narrative; ice, we are told, is the only component of Antarctic geography. Certainly the author's story owes little allegiance to Apsley Cherry Garrard's philosophy, expressed in The Worst Journey in the World - perhaps the best book ever written on Antarctica - that it is the spirit of man that has shaped that continent.

Man is conceded one resounding achievement - his success in establishing a tenuous foothold on the continent. Pyne's intense awareness of the special nature of man's relationship with The Ice has distinct parallels with the views of the bizarre and unexpected turn. The author announces that on Thanksgiving Day 1984 he bought himself an IBM/PC-compatible personal computer, with a colour/graphics card and spinwriter. He then devotes the rest of the book to the details of nine computer programs, printed in BASIC in the back of the book, for calculating ocean flows. The programming style is unstructured and virtually unreadable. We are caught in a melodrama of grand proportions: just when (at no small investment of concentration) we have come to appreciate, and have begun to understand, our narrator's deep geometric insight, he becomes infected with a classic, perhaps terminal, case of PC addiction. Insight is thrown away. He is transformed into, simply, a hacker.

There is thus a kind of moral lesson in this book. A diskette with Stommel's programs is available separately. The programs do run. One of them is babbling away on my computer screen right now. $\square$

William H. Press is Professor of Astronomy and Physics in the Harvard-Smithsonian Center for Astrophysics, 60 Garden Street, Cambridge, Massachusetts 02138, USA, and co-author of Numerical Recipes: The Art of Scientific Computing (Cambridge University Press, 1986).

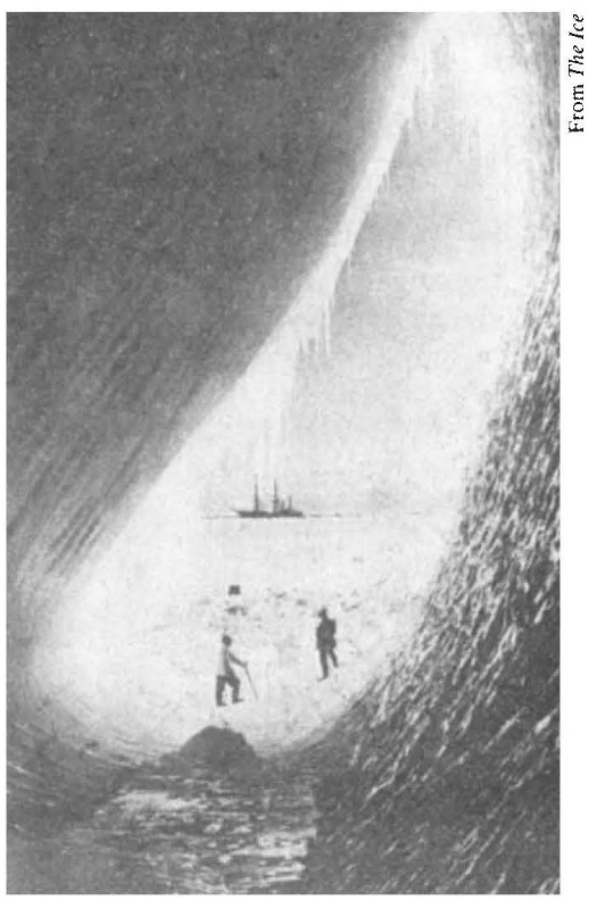

In perspective - the Antarctic exploration ship Terra Nova seen from an ice cave. Photograph taken by Herbert Ponting.

geographer, Yi Fu Tuan, who wrote that, "in open space once can become intensely aware of a place, and in the solitude of a sheltered place the vastness of space acquires a haunting presence". This presence has inspired Pyne to write intense and perceptive sections on the oceanography, geology, glaciology, art, 
literature and geopolitics of the Antarctic in prose that is at times powerful but also, over 400 pages, can occasionally be fatiguing.

It is The Ice, the forces which create and destroy it and the forces which it in turn influences, that dominate the book. Because over 60 per cent of the world's fresh water is locked into the Antarctic, and tabular bergs the size of Belgium are not uncommon, perhaps this preoccupation is understandable, if not particularly stimulating for the reader.

It is only where man makes an appearance, and the ice terranes and ice orrerys are relegated temporarily to the background, that a wider perspective becomes apparent. Pyne develops the thesis that The Ice imposed on explorers, as on artists, the need to develop not only special technologies but also to adopt new casts of thought. These concepts are analysed and expanded at some length in the book, but the result seems to offer little of substance

\section{When dark is light enough}

\section{Owen Gingerich}

Darkness at Night: A Riddle of the Universe. By Edward Harrison. Harvard University Press: 1987. Pp. 293. \$25, £19.95. "A GREAT cause of the night is the lack of
the Sun", says the innocent shepherd in $A s$
You Like It, and though we may chuckle
at his naiveté, few of us stop to ponder the
more profound alternative. "A great
cause of the darkness at night is the lack of
Suns". If the Universe is infinite and
randomly filled with stars, then any line
of sight must eventually reach a star,
and the vault of the heavens should be
aglow with the brilliance of an average
star's surface.

If you are convinced that the Universe is infinite and randomly filled with brightly shining stars (or galaxies of stars), then the darkness is a paradox. But if you believe that the Universe is either limited or not randomly filled with stars, then the darkness is a riddle to be solved. Hermann Bondi, who in the early 1950s accepted an infinite steady-state Universe, popularized the problem as "Olbers" paradox". He claimed that the red shift of the distant galaxies solved the puzzle, and that earlier astronomers could have deduced the idea of the expanding Universe merely from the darkness of the sky at night.

Since Bondi's Cosmology, "Olbers' paradox" has been part of the astronomers' vocabulary, and the problem of darkness at night has been the subject of to the scientist, and the humanistic perception, with which the author is credited on the jacket, although evident may well confuse the layman.

The author claims to have found in the Antarctic ice, "from core to margin, from polar plateau to open sea an allegory of matter". His thoughts about his allegorical discovery in, and return from, the icy vastness of the Antarctic seem to be encapsulated in the lines he quotes from Edgar Allen Poe's "Dreamland":

I have reached these lands but newly From an ultimate dim Thule

From a wild weird clime that lieth sublime Out of SPACE and out of TIME.

The space and time of the hauntingly beautiful Antarctic are there to be glimpsed in this, the author's own dreamland.

Derek Fordham, 66 Ashburnham Grove, Greenwich, London SE10 8UJ, UK, is Secretary of the Arctic Club and has travelled widely in polar regions.

The prize goes - somewhat ambiguously - to the remarkable insight of Edgar Allen Poe and to the independent and nearly forgotten calculations by Lord Kelvin. Harrison has resurrected both of these accounts, and he accepts their answer: stars simply do not shine long enough for there to be the necessary infinite number to dazzle the night-time sky. He describes how the Bondi-Gold redshift solution would indeed work for a steady-state cosmology but not for the bigbang model. At the last stop on the tour, Harrison recasts the Poe-Kelvin solution into a somewhat different form in order to show that there is an even better way to look at the problem. There simply is not sufficient energy in the Universe for the stars at night to be so many and bright.

As a cosmologist, Harrison seems to have withstood the critical examination of his peers, for his solution has appeared without refutation in technical journals. The extensive bibliography as well as the success of his detective work attests to his skills as a historian of science. But the swift, nutshell descriptions of astronomers of yore will give chills to sterner, more professionalized historians. I found the chaotic inconsistency of book titles, sometimes in their original tongues and sometimes in translation, rather careless, and I was distressed that an appendix devoted to "Digges on the Infinity of the Universe" nowhere states that this is, except for one small but crucial part, merely Digges's translation from Copernicus. And to label as "Stoic" any astronomer who accepted a bounded system of stars within unlimited empty space - such as Harlow Shapley in 1920 - is less than helpful.

Harrison is quite forgiving that Bondi popularized the "riddle" under the misnomer "paradox", and that he assigned it to Olbers instead of Cheseaux, who had specified the problem earlier. Indeed, Olbers had Cheseaux's book in his library, but must have forgotten about the Swiss astronomer's account of 1744 when he wrote his own paper in 1823 . Referring to Bondi, Harrison says, "Encumbered with one or two trifling historical inaccuracies, the riddle gained a new lease on life". His relaxed attitude may now stand him in good stead: since this book went to press, Frank Tipler has shown that Poe's solution of the riddle was given even earlier by the selenographer Johann Heinrich Mädler, and even that Poe knew of Mädler's speculations on this subject. Such are the pitfalls in an attempt at historical completeness! Nevertheless, Harrison's tour is nearly a tour de force, and certainly a fine example of science popularization. sions, from antiquity to Einstein, past Kepler, Kant and Kelvin, Cheseaux, Charlier and Fournier d'Albe - with stops at 15 possible solutions to the mystery.
Owen Gingerich is a Professor in the HarvardSmithsonian Center for Astrophysics, 60 Garden Street, Cambridge, Massachusetts 02138, USA. 